\title{
The mechanism of CNP-induced negative inotropic and positive lusitropic responses are dependent on SERCA activity in failing rat ventricle
}

\author{
Lise Román Moltzau ${ }^{1,2^{*}}$, Jan Magnus Aronsen ${ }^{2,3,4}$, Silja Meier ${ }^{1,2}$, Cam Nguyen ${ }^{1,2}$, Geir Christensen ${ }^{2,3}$, \\ Ivar Sjaastad ${ }^{2,3,5}$, Tor Skomedal ${ }^{1,2}$, Jan-Bjørn Osnes ${ }^{1,2}$, Finn Olav Levy ${ }^{1,2}$, Eirik Qvigstad ${ }^{1,2}$
}

From 5th International Conference on cGMP: Generators, Effectors and Therapeutic Implications Halle, Germany. 24-26 June 2011

\section{Background}

Natriuretic peptides increase in heart failure. C-type natriuretic peptide (CNP) generates cyclic 3',5' guanosine monophosphate (cGMP) by activating the NPR-B receptor in cardiomyocytes. There are studies showing CNP-induced negative inotropic and positive lusitropic responses in normal hearts, but less is known about the effects of CNP in failing hearts.

\section{Results}

We investigated the functional effects of CNP in heart failure and suggested that increased activation of SERCA is the main mechanism of CNP-induced negative inotropic and positive lusitropic responses. Increased SERCA activity could cause a faster $\mathrm{Ca}^{2+}$ removal from cytosol and thus less $\mathrm{Ca}^{2+}$ available for the myofilaments during contraction. Cyclic GMP levels, contraction and relaxation, $\mathrm{Ca}^{2+}$ transients, troponin I (TnI) and phospholamban (PLB) phosphorylation were measured in left ventricular muscle strips or cardiomyocytes from Wistar rats with heart failure 6 weeks after myocardial infarction. CNP increased cGMP levels and evoked negative inotropic and positive lusitropic responses concentration-dependently. TnI and PLB phosphorylation also increased in the presence of CNP. The functional responses to CNP were reduced in the presence of a PKG-blocker/ cGMP-analogue (Rp-8-Br-Pet-cGMPs), demonstrating

\footnotetext{
* Correspondence: I.r.moltzau@medisin.uio.no

'Department of Pharmacology, Faculty of Medicine, University of Oslo and

Oslo University Hospital, Oslo, Norway

Full list of author information is available at the end of the article
}

activation of the PKG pathway. In the presence of $\mathrm{CNP}, \mathrm{Ca}^{2+}$ transient amplitude and $\mathrm{Ca}^{2+}$ extrusion rate were increased. CNP elicited both negative inotropic and positive lusitropic responses in the presence of the L-type $\mathrm{Ca}^{2+}$ channel activator BAY K 8644, whereas in the presence of full activation of the cAMP system by isoproterenol these responses were not seen. This indicates that the downstream targets causing functional responses to CNP were already activated in the presence of isoproterenol. All these results could be explained by an increased SERCA activity and a reduced myofibrillar sensitivity to $\mathrm{Ca}^{2+}$ in the presence of CNP, due to increased phosphorylation of PLB and TnI, respectively. An obligatory role of SERCA activation was revealed in a mouse model with cardiomyocyte-specific excision of the SR $\mathrm{Ca}^{2+}$-ATPase gene (SERCA-KO). The functional responses to CNP were abolished in 8-week SERCA-KO mice compared to 4week SERCA-KO mice still possessing some SERCA activity.

\section{Conclusion}

The functional responses to CNP are mediated through the PKG pathway. Activation of SERCA thus seems to be the major and indispensable mechanism of CNPinduced functional responses in failing hearts.

\section{Author details \\ ${ }^{1}$ Department of Pharmacology, Faculty of Medicine, University of Oslo and Oslo University Hospital, Oslo, Norway. ${ }^{2}$ Center for Heart Failure Research, University of Oslo, Oslo, Norway. ${ }^{3}$ Institute for Experimental Medical Research, Faculty of Medicine, University of Oslo and Oslo University}


Published: 1 August 2011

doi:10.1186/1471-2210-11-S1-P49

Cite this article as: Moltzau et al.: The mechanism of CNP-induced

negative inotropic and positive lusitropic responses are dependent on SERCA activity in failing rat ventricle. BMC Pharmacology 2011 11(Suppl 1):P49.

Submit your next manuscript to BioMed Central and take full advantage of:

- Convenient online submission

- Thorough peer review

- No space constraints or color figure charges

- Immediate publication on acceptance

- Inclusion in PubMed, CAS, Scopus and Google Scholar

- Research which is freely available for redistribution 